\title{
Prevention and control of COVID-19: public health response in Puttalam District
}

\author{
Dinusha Fernando $^{1}$, Thushani Dabrera ${ }^{1^{*}}$, Udani Adhikary ${ }^{1}$, Dinej Chandrasiri ${ }^{1}$, Mahendra Arnold ${ }^{2}$ \\ ${ }^{1}$ Office of the Regional Director of Health Services, Puttalam District, Ministry of Health, Sri Lanka; ${ }^{2}$ \\ Ministry of Health, Sri Lanka
}

"Correspondence: thushanidabrera@yahoo.com

Dhttps://orcid.org/0000-0001-7526-2249

DOI: https://doi.org/10.4038/jccpsl.v26i5.8334

Received on 12 May 2020

Accepted on 22 May 2020

\begin{abstract}
Summary
Puttalam District has a diverse multi-ethnic and multi-religious population of 801,000 . It is an economic hub which provides salt, coconuts, vegetables, fish, eggs and poultry to the whole country. It also hosts one of the largest cement factories in the country and Lakvijaya power plant at Norochcholai supplying $56 \%$ of the electricity to Sri Lanka (1).

Puttalam was identified as a vulnerable area for the spread of COVID-19 by the district health authorities since there are many Chinese nationals working in industries and a large number of persons employed in Europe (mainly Italy) and Middle East. Due to the number of Italian migrant population, Wennappuwa is popularly known as "mini Italy". In this article, we highlight the successful control of COVID-19 outbreak through good public health response by foreseeing the future risk and advance preparation, timely decision making, regular communication with healthcare staff and inter sectoral collaboration.
\end{abstract}

\section{Public health response and its impact}

\section{Strategies}

The responsibility of prevention and control of COVID-19 lies with public health authorities of the district. In this context, several public health strategies were implemented with the objective of preventing the introduction and spread of COVID-19 in Puttalam.

\section{Preparedness of the preventive sector}

When the initial Chinese national patient was reported on 27 January 2020 (2), the district health team was made aware of the disease and planning was done to strengthen the public health response to face COVID-19 (3-5). Regional Director of Health Services (RDHS) Office functioned as the main coordinating body. Regional epidemiologist (RE) liaised with the central level and medical officers of 
health $(\mathrm{MOH})$. Planning, maternal and child health $(\mathrm{MCH})$ and mental health units were entrusted with different tasks on COVID-19 activities. Consultant Community Physician (CCP)-Planning was identified as the focal point to coordinate activities. In early March, a decision was taken to extend the opening hours of high risk $\mathrm{MOH}$ offices and to open on Sundays and public holidays. Regular meetings were held with heads of institutions to discuss the implementation of control measures, identify gaps and address the issues at ground level. A good communication system was established where all decisions, circulars, guidelines and other information was rapidly disseminated to healthcare institutions.

\section{Public health response}

A wide range of public health measures were applied to respond to the COVID-19 outbreak in the district. This included surveillance, contact tracing, quarantining, public awareness and inter-sectoral coordination.

\section{- surveillance}

From 27 January 2020, the Epidemiology Unit provided details of persons returning from China. The MOHs and public health inspectors (PHI) visited and house-quarantined the returnees for a period of 14 days. They were educated about the symptoms and were reuested to contact the health authorities if such symptoms appeared. The PHI visited these premises daily and a status update was submitted to the Epidemiology Unit.

\section{- Contact tracing}

With the first COVID-19 positive case in Puttalam detected on 14 March 2020, contact tracing was initiated by the public health staff. As the case load increased, the number of close contacts to be traced also increased. All details of the close contacts wre recorded and were put under a 14-day house quarantine. The $\mathrm{MOH}$ and $\mathrm{PHI}$ visited the premises and ensured that strict house quarantine was maintained. Military and police were separately tracing the contacts of patients.

\section{- Quarantining}

At the initial stage in January, public health authorities took action to quarantine for 14 days all the Chinese engineers working at Norochcholai power plant who have returned from Wuhan after the Chinese New Year. Authorities of the power plant were madeaware of the quarantine process and $\mathrm{MOH}$ with the district health team streamlined the process of quarantine.

Rapid community spread in Italy resulted in many returnees mainly from Dankotuwa, Wennappuwa, Nattandiya and Mahawewa MOH areas. The mandatory quarantining in centres began on 10 March 2020. Returnees from Italy, Iran and South Korea were sent to quarantin centres directly from the airport. District health authorities took steps to house-quarantine nearly 2000 returnees who had returned before this date. The $\mathrm{MOH}$ and PHIs periodically visited and ensured the strict enforcement of house-quarantine. House quaantining of such a large number was an uphill task. There was an instance where a MOH had to get a court order to house-quarantine persons who did not adhere to the instructions of health authorities.

When a returnee from Indonesia was found positive, it was a challenge to house-quarantine his 70 contacts. Health authorities with the support of the Puttalam Urban Council, Divisional Secretary, Army and the Police converted a school into a quarantine cener. An experienced supervising PHI (SPHI) voluntarily based himself in the centre to collect all relevant data and prevent cross-infection within the centre. There was no spread of disease from the identified positive patients and their contacts due to stingent measures taken during early identification, isolation and quarantine. Figure 1 shows the spread of COVID-19 cases from 1 March to 15 April 2020. 


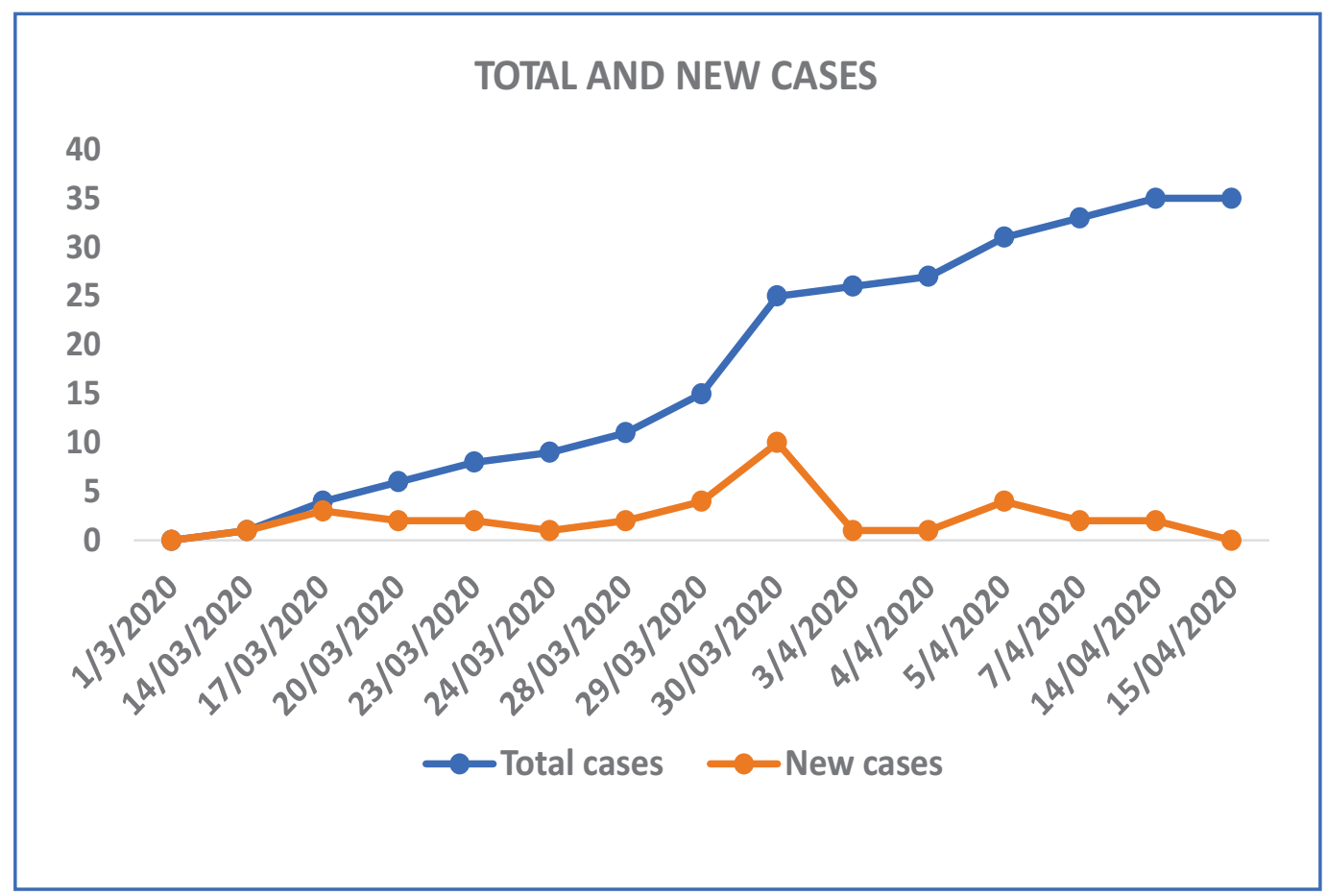

Figure 1: Number of total and new cases from 1 March to 15 April 2020 in Puttalam District

\section{- Public awareness}

Public health staff visited supermarkets and places with high public patronage, educated the staff, displayed posters developed by the RDHS office on disease prevention measures, hand washing and health habits. The supermarkets were requested to establish and washing facilities at the entrance.

Thalawila Church Festival attended by nearly 100,000 Catholic devotees was held in early March. The risk of disease spread from returnees from Italy was communicated by the Regional Director of Health Services (RDHS) of Puttalam District to the Bishop of Cilaw who alerted the parishes in writing. A health centre was set up in the festival premises and preventive health messages were broadcasted over the public address system. Several hand washing facilities were established.

Awareness was conducted at the community level by all $\mathrm{MOH}$ offices using public address systems. Uniform disease prevention messages, instructions on symptoms and treatment seeking were communicated to the general public. At the hospital outpatient departmets (OPD), awareness was done by medical officer-public health and infection control nursing officers. Pregnant mothers were educated at the clinics and in the field by Public Health Midwives.

\section{- Inter-sectoral coordination}

The control measures in COVID-19 needed the assistance of many stakeholders. The requirements were extensive and included manpower, transport, security, locations, food and funding. The health sector played the lead role and obtained the support from Distrct and Divisional Secretaries of Puttalam District, Armed Forces, Police, Sri Lanka Transport Board, and the educational and provincial authorities.

A large number of Catholics live in the district and some areas are inhabited predominantly by Muslims. Support of religious leaders was obtained to disseminate messages to the members of the community who have close links with churches and mosques and to nsure that the community adheres to the preventive measures. 


\section{- Preparedness of the curative health sector}

At the time of the first case reported in the district there was no designated hospital identified for isolation. However, space for isolation in Marawila, Puttalam and Chilaw hospitals had been prepared in advance by the district health team to cater the nitial patients. Later, the Ministry of Health named Base Hospital Marawila and District General Hospital
Chilaw as designated COVID-19 isolation centers. The facilities were upgraded with a 60-bed capacity (Figures 2 and 3). Former Voice of America Statin at Iranawila was converted to a 40 bed COVID-19 Management Centre within 20 days with the support of the armed forces. Two teams from BH Marawila and Puttalam were trained to do swab collection for testing (PCR).

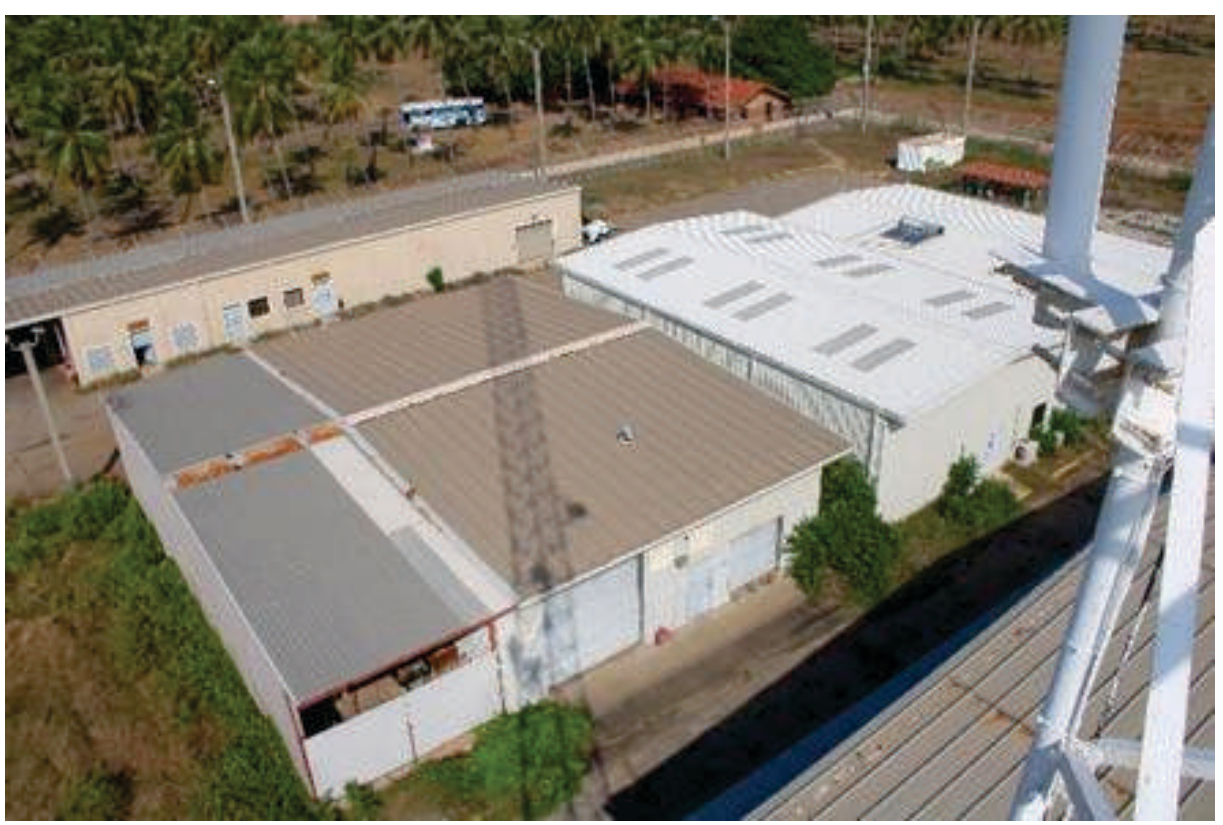

Figure 2: Former VoA Complex Iranawila (aerial view)

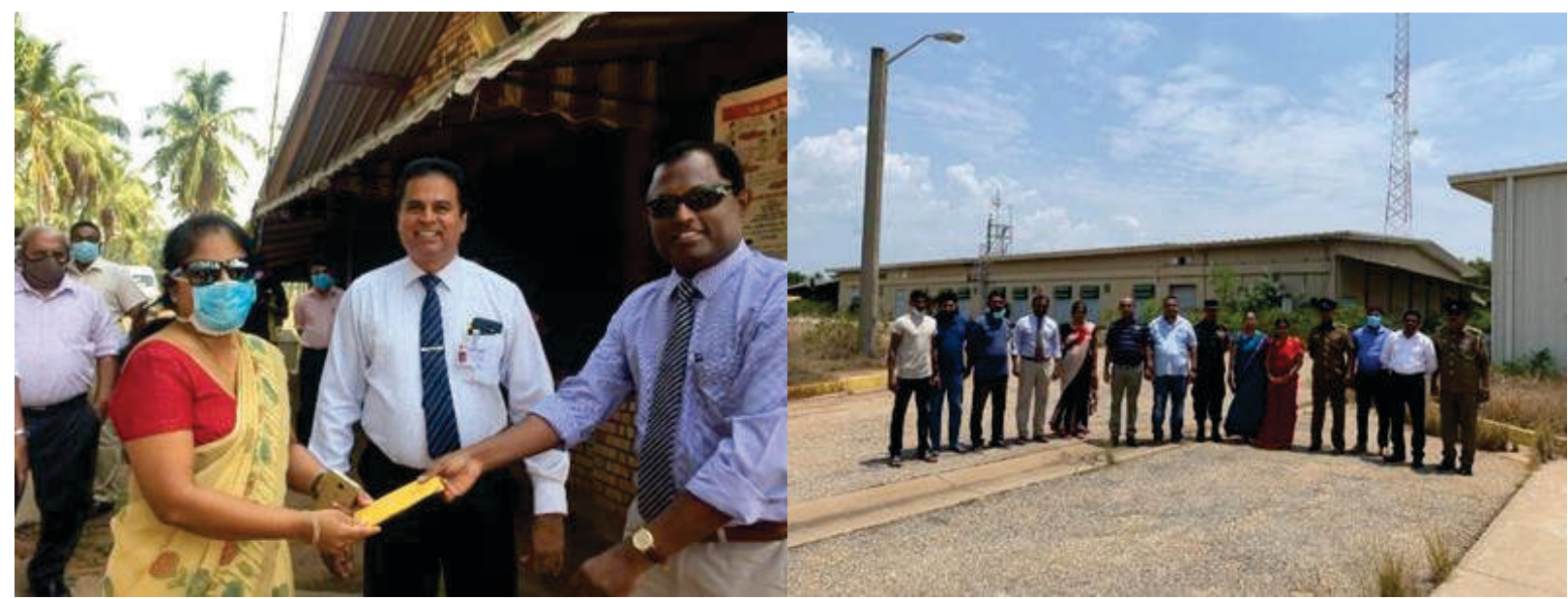

Figure 3: Keys to complex handed over to RDHS and inspection of complex by district team

Apart from the two main hospitals, heads of institutions of other base hospitals and Type A divisional hospitals were made aware of the situation and were requested to prepare the institutions to accept suspected patients if needed. Isolation facilities were established in all four base hospitals (Figure 4). Hand washing facilities were made available in all healthcare institutions. 


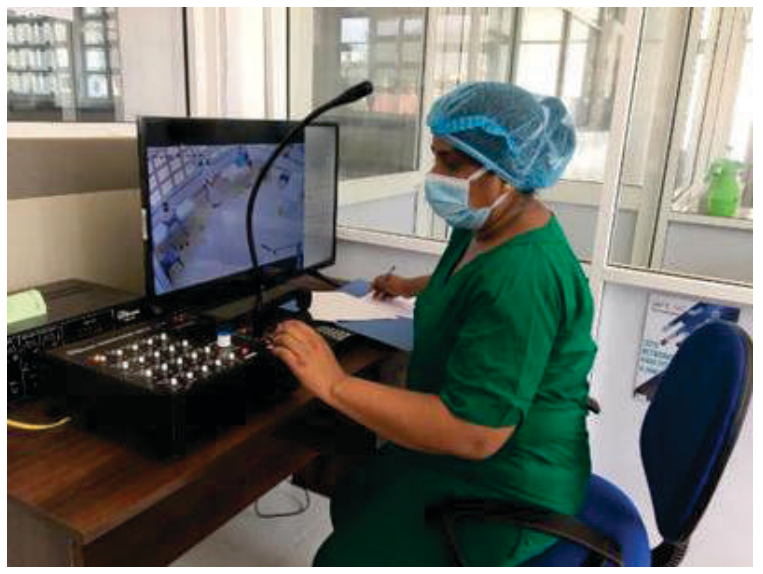

Figure 4: Isolation Centre at BH Marawila with new technology

Few primary medical care units (PMCU) in areas with a high number of overseas returnees were closed during the high-risk period. This was due to inadequate space and facilities for triage and the risk of spread of disease from these centers. Patients seeking care from these PMCUs were directed to the nearest divisional or base hospital. However, arrangements were made to provide the monthly supply of drugs for clinic patients (Figure 5).

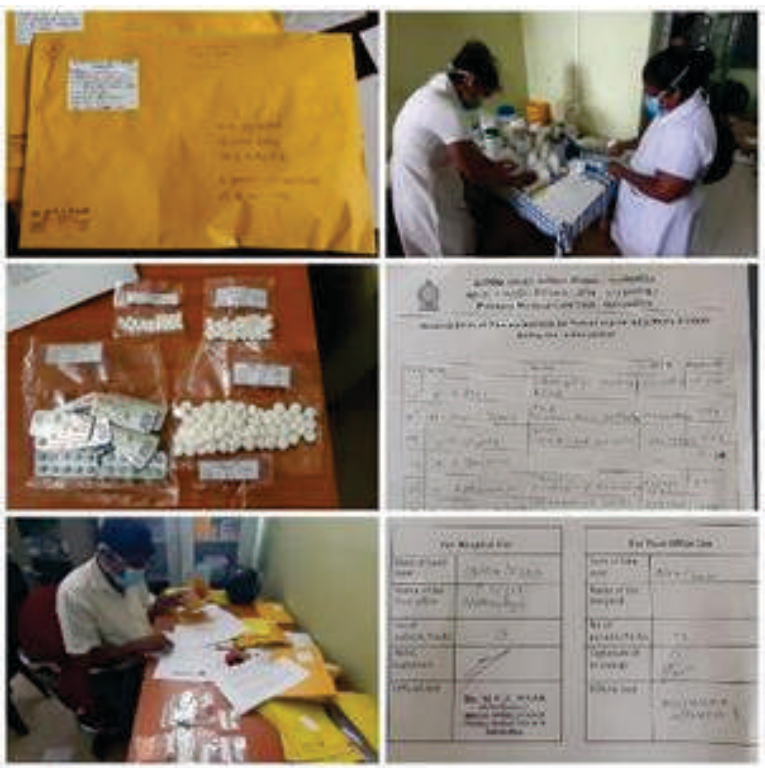

Figure 5: PMCUs arranging supply of clinic drugs by post

\section{Challenges faced}

With an increasing number of positive cases being reported, contact tracing was a challenge to the
MOHs with inadequate PPE, transport facilities and meals for field health staff as the district was under curfew. PPE were obtained from the Ministry of Health and donors. Extra vehicles and staff for high risk $\mathrm{MOH}$ areas were mobilized from low risk $\mathrm{MOH}$ areas. Internal arrangements were made to provide meals for the staff who were virtually doing a $24 / 7$ duty.

At the initial stage, the house-quarantine was not strictly adhered to by some people. One reason was that the community who were mobile did not come into terms with sudden movement restriction. Public health staff took extra effort with the assistance of the police to ensure strict house quarantine. Gradually, the community accepted this mandatory requirement and cooperated with the preventive measures. Influence of religious leaders also facilitated this process.

\section{Strengths and gaps}

Foreseeing the future risk and advance preparation, timely decision making, regular communication with preventive and curative healthcare staff, inter sectoral collaboration with the other agencies resulted in good public health response and successful control of COVID-19. This was achieved despite Puttalam district being a high-risk area with a large number of overseas returnees and 35 cases being detected. No case being detected within the district since 14 April 2020 shows the success of continued public health response. The conduction of the church festival with 100,000 devotees was a disaster in waiting which the health sector could not convince to postpone can be considered as a gap.

\section{Author Declaration}

Acknowledgements: The authors gratefully acknowledge the support of all heads of health institutions in the district and medical officer of planning of RDHS office.

Author contributions: All authors contributed to the drafting of the first version of the manuscript. All authors read and approved the final manuscript. 


\section{References}

1. Department of Census and Statistics. District Statistical Handbook, Puttalam. Colombo: Ministry of National Policies and Economic Affairs. Available from: http://www.statistics.gov.lk/District StatH Book.asp?District=Puttalam\&Year=2019

2. Daily Mirror. Chinese woman at IDH tested positive for coronavirus. Available from: http://www. dailymirror.lk/top_story/Chinese-woman-at-IDHtested-positive-for-coronavirus/155-181996. Accessed 11 May 2020.

3. World Health Organization. Strengthening the health system response to COVID-19. Available from: http://www.euro.who.int/_data/ assets/ pdf_file/ 0003/436350/strengthening-health-systemresponse-COVID-19.pdf?ua=1.

4. Australian Government. Department of Health. Australian Health Sector Emergency Response Plan for Novel Coronavirus (COVID-19). Available from: https://www.health.gov.au/ resources/publications/ australian-health-sector-emergency-response-planfor-novel-corona virus-covid-19-short-form.

5. David M Hartley, Eli N Perencevich. Public health interventions for COVID-19. emerging evidence and implications for an evolving public health crisis. JAMA 2020;323(19):1908-1909. DOI: 10.1001/ jama.2020.5910. 